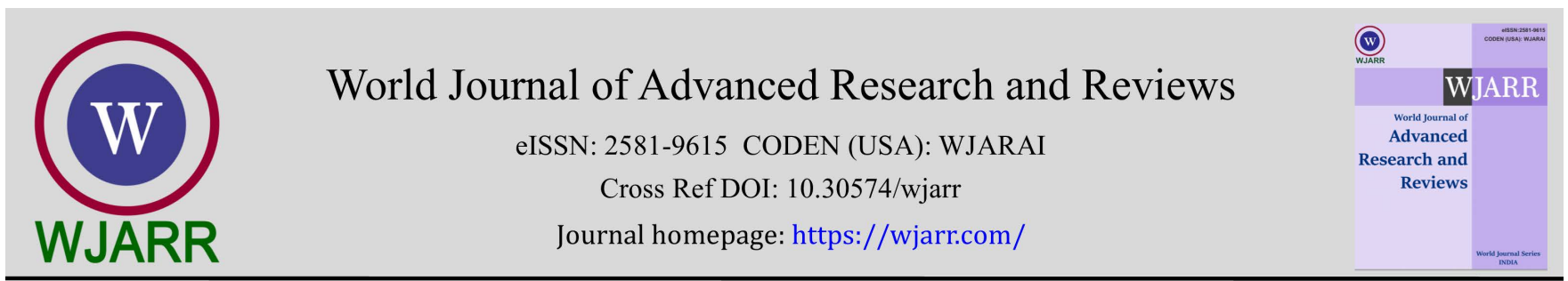

(RESEARCH ARTICLE)

\title{
Impact of problematic internet use on the academic stress and academic performance among adolescents in selected school, Kochi Kerala, India
}

\author{
Preeti Mathew * and Raman K \\ Saveetha Institute of Medical Science and Technology, Thandalam, Chennai, India.
}

World Journal of Advanced Research and Reviews, 2021, 12(02), 109-119

Publication history: Received on 20 September 2021; revised on 24 October 2021; accepted on 26 October 2021

Article DOI: https://doi.org/10.30574/wjarr.2021.12.2.0549

\begin{abstract}
The internet is recognized as a medium for information exchange, in various fields such as in academic research, entertainment, communication and commerce, across the world. Continuous use of internet results in a lot of psychological and mental disorders like anxiety, depression, stress and obsessive-compulsive disorder; as observed in many of the studies carried out recently. Recently, Problematic Internet Use has become a global phenomenon that causes serious problem to the affected individual leading to impairment in psychological well-being by causing excessive stress and affecting the individual's academic performance. The present study aimed to assess the Problematic Internet Use and its relationship with Academic Stress and Academic Performance among adolescents in selected schools, Kochi, Kerala, India. The study was conducted in Private Aided School, in Muvattupuzha Taluk of Ernakulam Dist, Kerala. A cross-sectional design with a quantitative approach was selected, and the study was conducted in July 2018 among 125 adolescents and participants were selected using random sampling technique. The samples were provided with a self-administered questionnaire after obtaining written consent from their parents and the students. The findings of the study revealed that 59.20\% had mild Problematic internet addiction. $65 \%$ of the adolescents reported moderate stress and $32 \%$ had mild stress. Academic performance-wise, $60 \%$ of the adolescents were found to be average in the studies. Karl-Pearson coefficient indicated a significant relation between Academic Stress ( $\mathrm{r}=-1$ and $\mathrm{p}<0.001)$. Based on the findings one can conclude that the adolescents who were having intern et addiction were found to have detrimental effects both in their Academic Performance and academic stress to some extent. As a result, the use of internet in normal limits or in moderation may not cause potential harm to their adolescents.
\end{abstract}

Keywords: Academic Performance; Academic Stress; Adolescents; Problematic Internet Use

\section{Introduction}

Extreme or poorly controlled pre-occupations characterize Internet Addiction. Internet addiction is defined as the inability to control one's urge to use the internet, which eventually causes psychological, social, school, and/or work difficulties in one's life. As the Individuals addicted to the internet may use the internet for prolonged periods detaching themselves from other social contacts and concentrate almost entirely on the internet rather than the broader life events. Adolescents with Problematic internet addiction usually suffer from problems with their daily routines, school performance, family relationships and moods.

Globally the prevalence of Problematic Internet Use considerably varies from one country to another. In a prevalence study carried out in Europe in 2014, it was observed that adults had a prevalence of 7.9\% and adolescents $4.4 \% .1 .6 \%$ of Korean adolescents reported internet addiction with $38 \%$ of them at risk for internet addiction in future. Further in recent studies, prevalence was found to be up by $26 \%$ in adolescents.

\footnotetext{
* Corresponding author: Preeti Mathew

Saveetha Institute of Medical Science and Technology, Thandalam, Chennai, India.

Copyright (C) 2021 Author(s) retain the copyright of this article. This article is published under the terms of the Creative Commons Attribution Liscense 4.0.
} 
Many study findings conclude that stress and internet addiction are closely related. Previous researchers such as Ah and Jeong, Cho, Suh and Lee have revealed that stress is one of the crucial antecedents of Internet addiction for adolescents. Therefore, adolescents who use more internet are more stressed than normal adolescents. ${ }^{1-4}$. According to General Strain theory, a variety of stress experienced by adolescents might cause negative emotions, which subsequently causes problem behaviors. Among the various types of stress, Academic Stress is the most salient and prevalent stressor for adolescents.

Substantial research has consistently shown that Academic Stress is related to psychological problems such as depression, anxiety, and insomnia for adolescents. However, less is known regarding the psychological mechanism associated with Academic Stress and its link with Internet addiction. Alavi et al. in a study examined the relationship between psychiatric symptoms of Internet addiction in Isfahan University students; showed that there is a significant positive correlation between psychiatric disorders such as depression, anxiety, stress, hypochondriasis, compulsion, interpersonal sensitivity, aggression, and paranoia, phobias, psychosis and Internet addiction. Jafari and Fathizade also in their study observed that there was a significant positive relationship between Internet addiction and each of the clinical variables of depression, anxiety, stress and social phobia. ${ }^{5}$

Also, Internet addiction has been linked to stress and negative emotions among adolescents causing emotional instability among adolescents. It was further reported that these adolescents often had difficulties in balancing classes, tests, assignments, extra-curricular activities, and social life. Inability to handle these challenges affected their physical, mental, emotional, cognitive, and behavioral functions; leading to considerable amount of anxiety and stress. They were not able to handle stress well ${ }^{6}$ which led them to lose their motivation to engage in their studies ${ }^{7}$. Consequently, their Academic Performance deteriorated $8,9,10$ and performed badly in their exam.

Samaha \& Hawi, summed up that student with poor academic performance had higher level of stress. ${ }^{11}$ Stress was considerably increased in students as the free time they got was consumed in using internet resulting in very less time for study. Similar findings were also observed by Safree, Yasin \& Dzulkifi ${ }^{12}$ and Khan, Altaf and Kausar ${ }^{13}$. Based on the above-mentioned facts regarding Problematic Internet Use and its possible side-effects on academic performance leading to considerable amount of academic stress, the researcher felt is as necessary to investigate these variables among school students. Thus, a study with an aim to assess the effect of Problematic Internet Use on stress and academic performance among adolescents was conducted.

\section{Objectives}

- Assess the degree of Problematic Internet Use, Academic Stress and Academic Performance among adolescents.

- Find a correlation between Problematic Internet Use and Academic Stress, Academic Performance among adolescents.

- Compare between problematic internet users and non-Problematic Users.

- Find an association between Problematic Internet Users and selected demographic variables

\section{Material and methods}

\subsection{Study design and sample}

The present descriptive correlation study involved 125 adolescents who had been selected using cluster sampling methods from among all the adolescents studying in 8th, 9th and 10th standard of private aided schools in Muvattupuzha Thaluk, Ernakulam.

\subsection{Measurements}

- Socio-demographic characteristic consists of Age, Gender, Std/ Class, Family Income

- Information on Internet Usage Pattern: consists of information pertaining to Usage of the internet, Place of internet access, Purpose of internet used, Application used, Average duration of access -Per week, per day, Time of the day when the internet is accessed most and Activities Preferred online

\subsection{Problematic Internet Use Questionnaire}

A standardized tool developed by Zsolt Demetrovics, Beatrix Szeredi, and Sándor RózsaD (2008) ${ }^{14}$ to screen internet addiction was used after obtaining among adolescents. Permission to use the tool from the author was also obtained. 
The tool is a comprehensive measure used to assess essential aspects of Problematic Internet Use consisting of 18 items with three domains.

Obsession, neglect and control disorder. Cronbach's alphas for the standardized tool were found between 0.74 and 0.87 for all the three subscales. The score of questionnaires ranged from 18-90, the highest the score, the greater the dependence on the internet. The score ranged as No PIU: 18-36, Mild PIU: 36-84, Moderate PIU: 54-72 and Severe PIU: 72-90.

\subsection{Student Stress Inventory (SSI)}

Was developed by Mohammed Aziz Shah Mohammed Arip, 201515 to measure the level of distress among students. It contained 40 items to measure four subscales: Physical (10 items), Academic (10 items), Inter Personal Relationship (10 items), Environmental factor (10 items). The scale ranged from Never to Always with a score of 1-4. Student Stress Scale had a good content validity with an overall rating of $80.5 \%$ and a high- reliability coefficient of 0.85 . The scoring and interpretation were as follows: 40-80 mild stress, 81-120 moderate stress, 121-160 severe stress.

\subsection{Academic Achievement}

The overall marks obtained by the adolescents for various subjects in the previous two terms in the present academic session were collected from school records and the average of the terms were obtained. The students who had a score of 80 and above had Excellent Academic Achievement, 60-80 reflected a Good Achievement. 40-60 reflects Average Academic Achievement and those with less or equal to 40 had Poor Academic Achievement.

\subsection{Data collection and Ethical considerations}

The ethics committee of the Institution approved this study. The data were collected after obtaining initial permission from the Principal of the selected school. The subjects were requested for authorization to be signed by their parents as each of them were minor. Anonymity was guaranteed by assigning, subject code, and it was further explained to subjects that Participation in the survey was voluntary and they had the chance to withdraw from the study at any point of time. Data was collected during the free period, in the classrooms in the presence of the investigator. The tool was administered to the subjects, and the subjects took almost 45 minutes to complete the questionnaire. Doubts if any cleared at the end.

\subsection{Statistical Analysis}

Descriptive statistics like frequency, percentage were calculated for socio-demographic data, Mean and Standard deviation were used to assess Problematic Internet Use, Academic Stress and Academic Performance. Inferential statistics like Pearson correlation to assess the correlation between variables and the Chi-square was used to test the association of Problematic and Non- Problematic Internet Users with selected socio-demographic variables and independent t-test was used to compare the difference between Problematic and Non-Problematic Internet Users.

\section{Results and discussion}

\subsection{Study Sample Characteristics}

Table 1 and Table 2 and figure 1, 2 and 3 consists of a summary of the sociodemographic and internet usage pattern summarized. Thirty -two percent of the adolescent belonged to age group 13-14yrs, 40\% in the age group 14-15 yrs. And $28 \%$ in the age group of $15-16$ yrs. Of 125 subjects, majority, $60 \%$ of them were male with $34 \%$ of them studying in 10th standard. More than $50 \%$ of the adolescents belonged to the high-income group. All the adolescents had access to the internet, with more than half (52\%) of them using the internet in their own house and using the internet for academic purpose. $64 \%$ of the adolescents used the following application: e-mail, mass media, chat rooms, interactive games, online shopping, educational purpose, downloading or listening to music. 51\% of the student's accessed the internet for an average of $24 \mathrm{hrs}$./wk., with $18 \%$ of them accessing the internet for more than 4 hrs/ day. Thirty-two percent of adolescents preferred to access the internet in the morning and $28 \%$ of them in afternoon. Activities preferred online by majority (62\%) of subjects were gaming, instant messaging, social networking, watching Netflix, seeking information about education, online shopping and email. 
Table 1 Percentage-wise distribution of Adolescents with Problematic Internet Use according to socio-demographic variables $(\mathrm{N}=125)$

\begin{tabular}{|c|c|c|}
\hline Variables & $\mathbf{F}$ & $\%$ \\
\hline \multicolumn{3}{|l|}{ Age (years) } \\
\hline $13-14$ & 40 & 32 \\
\hline $14-15$ & 50 & 40 \\
\hline $15-16$ & 35 & 28 \\
\hline \multicolumn{3}{|l|}{ Gender } \\
\hline Male & 75 & 60 \\
\hline Female & 50 & 40 \\
\hline \multicolumn{3}{|l|}{ Class } \\
\hline $8^{\text {th }}$ Std & 40 & 32 \\
\hline $9^{\text {th }}$ Std & 42 & 33.6 \\
\hline $10^{\text {th }} \mathrm{Std}$ & 43 & 34.4 \\
\hline \multicolumn{3}{|l|}{ Family income } \\
\hline$>$ Rs. 126,360 & 69 & 55.2 \\
\hline Rs. $63,182-126,356$ & 23 & 18.4 \\
\hline Rs. 47,266-63178 & 11 & 8.8 \\
\hline Rs. $31,591-47262$ & 21 & 16.8 \\
\hline Rs. $18,953-31589$ & 1 & 0.8 \\
\hline Rs.6327-18949 & 0 & 0 \\
\hline$\leq$ Rs. 6323 & 0 & 0 \\
\hline Total & 125 & 100 \\
\hline
\end{tabular}

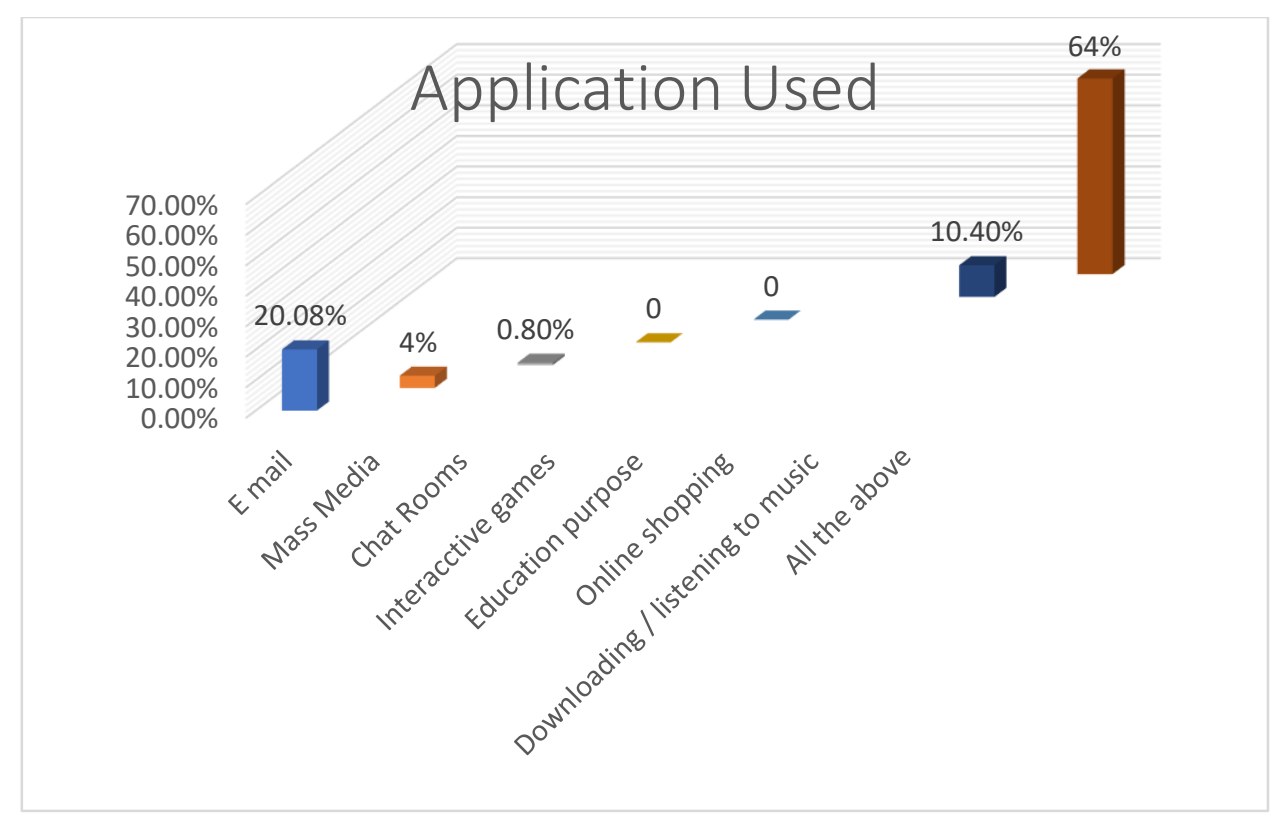

Figure 1 Bar diagram showing the Percentage distribution of Application used Online 


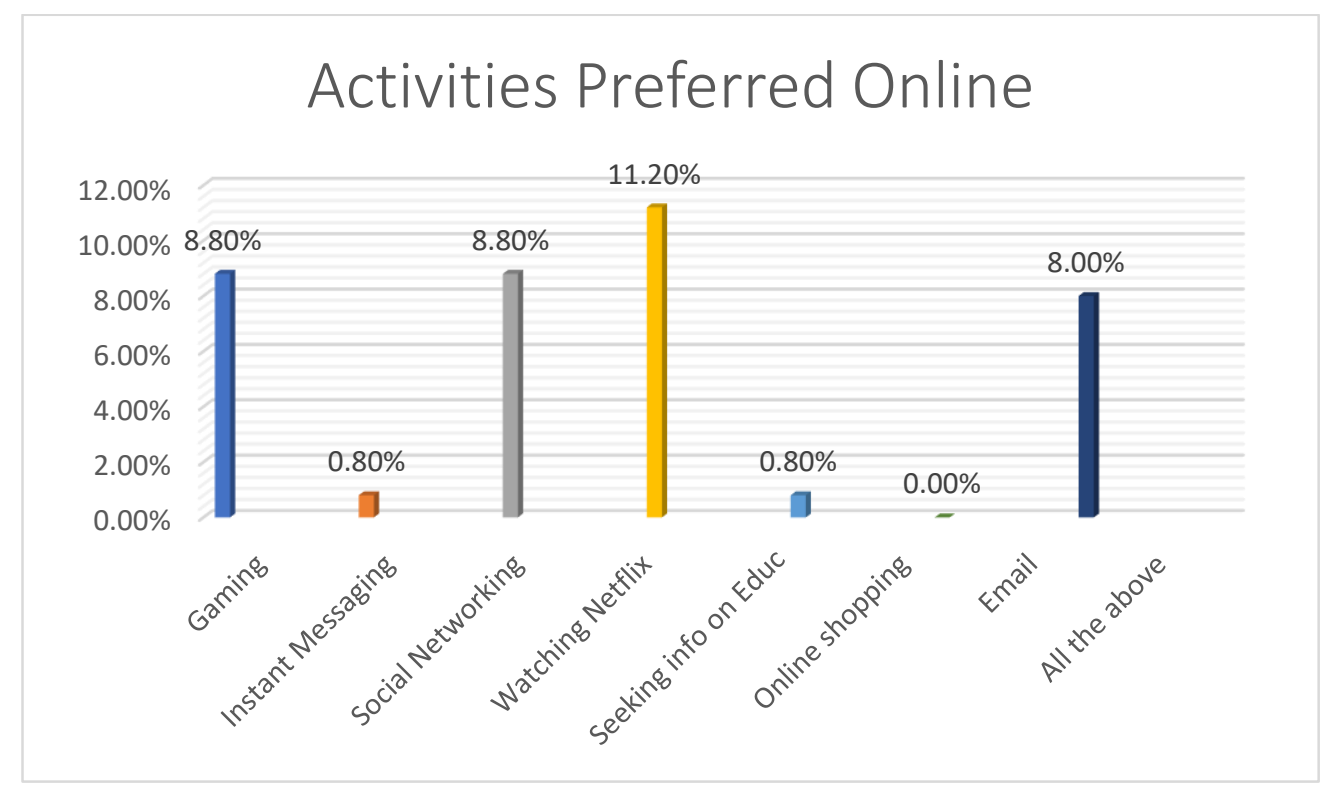

Figure 2 Bar diagram showing the Percentage distribution of Activities Preferred Online

Table 2 Percentage distribution of Adolescent with Problematic Internet Use according to information about internet use $(\mathrm{n}=125)$

\begin{tabular}{|l|c|c|}
\hline Variables & N & \% \\
\hline Internet usage & 108 & 86.4 \\
\hline Yes & 17 & 13.6 \\
\hline No & 65 & 52 \\
\hline Place of internet access & 11 & 8.8 \\
\hline Own house & 1 & 0.8 \\
\hline Friend's house & 23 & 18.4 \\
\hline Internet café & 8 & 6.4 \\
\hline School Library & 1 & 0.8 \\
\hline Public Places & 16 & 12.8 \\
\hline Relatives Home & 39 & 29.6 \\
\hline Combination of the above & 23 & 18.4 \\
\hline$\leq 6$ hours & 63 & 50.4 \\
\hline 12 hours & 59 & 47.2 \\
\hline 24 hours & 27 & 21.6 \\
\hline The average duration of access per day \\
\hline$<30$ min & 16 & 12.8 \\
\hline 1-2 hour & 23 & 18.4 \\
\hline $2-3$ hour & 40 & 32 \\
\hline$\geq 4$ hours & 35 & 28 \\
\hline Time of day when the internet is accessed most \\
\hline Morning & 18 & 14.4 \\
\hline Afternoon & 13 & 10.4 \\
\hline Evening & 15.2 \\
\hline Night & \multicolumn{2}{|l}{} \\
\hline Combination of the above & \multicolumn{2}{|l}{} \\
\hline
\end{tabular}




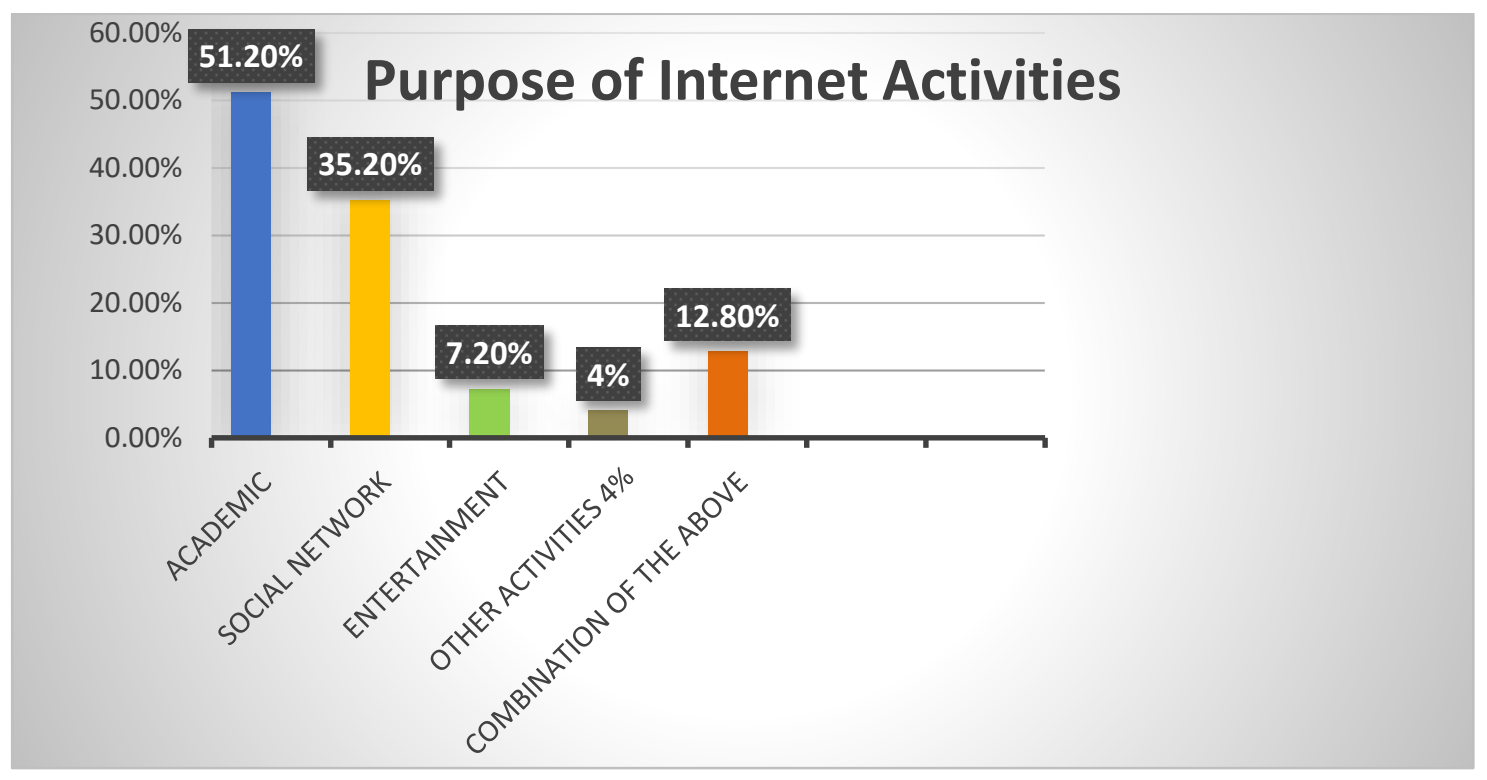

Figure 3 Pie diagram showing Purpose of Internet Activities

Table 3 Degree and Mean, SD of Problematic Internet Use, Academic Stress and Academic Performance among adolescents with Problematic Internet Use ( $\mathrm{N}=125)$

\begin{tabular}{|c|c|c|c|c|}
\hline Variables & Range of Score & $\mathbf{N}$ & $\%$ & Mean \pm SD \\
\hline \multicolumn{4}{|c|}{ Problematic Internet Use (PIU) } & \multirow{5}{*}{$33.9 \pm 14.2$} \\
\hline No PIU & $18-36$ & 78 & 62.40 & \\
\hline Mild PIU & $36-54$ & 35 & 28.00 & \\
\hline Moderate PIU & $54-72$ & 11 & 08.80 & \\
\hline Severe PIU & $72-90$ & 01 & 00.80 & \\
\hline \multicolumn{4}{|l|}{ Academic stress } & \multirow{5}{*}{$86.5 \pm 13.8$} \\
\hline No stress & $\geq 40$ & 01 & 00.80 & \\
\hline Mild stress & $40-80$ & 41 & 32.80 & \\
\hline Moderate stress & $80-120$ & 81 & 64.80 & \\
\hline Severe stress & $120-160$ & 02 & 01.60 & \\
\hline \multicolumn{4}{|c|}{ Academic Performance } & \multirow{5}{*}{$60.5 \pm 10.2$} \\
\hline Excellent & $\leq 80$ & 04 & 03.20 & \\
\hline Good & $60-80$ & 46 & 36.80 & \\
\hline Average & $40-60$ & 75 & 60.00 & \\
\hline Poor & $\geq 40$ & 00 & 00.00 & \\
\hline
\end{tabular}

Table 3 depicts the degree and mean \& standard deviation of Problematic Internet Use, Academic Stress and academic performance. Of the 125 adolescents, only $1(0.80 \%)$ reported Mild PIU, $11(08.80 \%)$ had moderate PIU, and 35 (62.40\%) had severe PIU with an overall mean and SD were $33.9 \pm 14.2$ Most of the adolescents $81(64.80 \%)$ had moderate Academic stress, and 41 (32.80\%) had mild stress, and the Mean and SD was $86.5 \pm 13.8$. 
On assessing the academic performance, only 4 (3.20\%) had excellent academic performance, 46 (36.80\%) had reported good Academic Performance and 75 (60\%) average performance. The Mean and SD were 60.5 \pm 10.2 .

Table 4 Comparison between non- Problematic Internet Users and Problematic Internet Users with the Academic Stress and Academic Performance among adolescents with Problematic Internet Use using independent t-test. (N=125)

\begin{tabular}{|l|c|c|c|}
\hline Variable & $\begin{array}{l}\text { No Problematic Internet User } \\
\text { (Mean } \pm \text { SD) }\end{array}$ & $\begin{array}{l}\text { Problematic Internet User } \\
\text { (Mean } \pm \text { SD) }\end{array}$ & p-value \\
\hline Academic stress & $83.45 \pm 11.75$ & $91.79 \pm 15.43$ & $0.001^{*}$ \\
\hline Academic Performance & $61.76 \pm 10.93$ & $58.6 \pm 8.60$ & 0.094 \\
\hline \multicolumn{2}{|c|}{ * Significant difference at 0.001}
\end{tabular}

On comparing non-Problematic users and Problematic users with variables Academic Stress using independent $\mathrm{t}$-test, there was a significant difference seen for Academic Stress $(\mathrm{P}<0.001)$. However, no difference was seen on comparing Problematic Internet Users and Non-Problematic Internet Users with the variable academic performance. (Table 4)

Table 5 Correlation of Problematic Internet Use, Academic Stress and Academic Performance scores among Adolescents with Problematic Internet Use (N-125)

\begin{tabular}{|l|c|c|c|}
\hline Variable & Problematic Internet Use & Coefficient r & p-value \\
\hline Academic Stress & $91.79 \pm 15.43$ & 0.307 & $0.001^{*}$ \\
\hline Academic performance & $58.6 \pm 8.60$ & -0.174 & 0.052 \\
\hline \multicolumn{2}{|c}{${ }^{*}$ Statistically significant at 0.001}
\end{tabular}

On Correlating Problematic Internet Use with Academic Stress and Academic Performance using Karl Pearson correlation coefficient, a meaningful positive relationship was seen between Problematic Internet Use and Academic Stress (r-0.307, p- 0.001). Therefore, it can be inferred based on the findings that with a significant increase in Excess Internet Use among adolescents, adolescents may experience significant academic distress.

On correlating Problematic Internet Use with academic performance, a negative relation ( $\mathrm{r}=-0.174)$ was seen, but the difference was not statistically significant. (Table 5). From the findings, it is inferred that with surplus use of internet leads to a decline in Academic Performance.

Table 6 Association between Problematic Internet Use and Non-Problematic Internet use among adolescents with Problematic Internet Use elected demographic variables (N-125)

\begin{tabular}{|c|c|c|c|}
\hline Variables & No Problematic Internet Use n (\%) & Problematic Internet Use n (\%) & p-value \\
\hline \multicolumn{4}{|l|}{ Family income } \\
\hline$>$ Rs. 126,360 & $50(72.5)$ & $19(27.5)$ & \multirow{5}{*}{$0.042^{*}$} \\
\hline Rs. $63,182-126,356$ & $12(52.2)$ & $11(47.8)$ & \\
\hline Rs. 47,266-63178 & $7(63.6)$ & $4(36.4)$ & \\
\hline Rs. 31,591-47262 & $8(38.1)$ & $13(61.9)$ & \\
\hline Rs. $18,953-31589$ & $1(100)$ & 0 & \\
\hline \multicolumn{4}{|c|}{ Purpose of internet activities } \\
\hline Academic & $41(64.1)$ & $23(35.9)$ & \multirow{5}{*}{$0.022^{*}$} \\
\hline Social network & $30(68.2)$ & $14(31.8)$ & \\
\hline Entertainment & $1(11.1)$ & $8(88.9)$ & \\
\hline Other activities & $4(80)$ & $1(20)$ & \\
\hline Combination of above & $2(66.7)$ & $1(33.3)$ & \\
\hline
\end{tabular}


Table 7 Association of the level of Problematic Internet Use among adolescents with selected demographic variables $(\mathrm{N}-125)$

\begin{tabular}{|c|c|c|c|}
\hline Variables & $\begin{array}{l}\text { No Problematic Internet } \\
\text { Use n (\%) }\end{array}$ & $\begin{array}{l}\text { Problematic Internet } \\
\text { Use n (\%) }\end{array}$ & p-value \\
\hline \multicolumn{4}{|l|}{ Applications used } \\
\hline Email & $22(84.6)$ & $4(15.4)$ & \multirow{5}{*}{$0.001^{*}$} \\
\hline Mass media & $5(100)$ & 0 & \\
\hline Chat room & 0 & $1(100)$ & \\
\hline Downloading/ listening to music & $11(84.6)$ & $2(15.4)$ & \\
\hline Combination of the above & $40(50)$ & $40(50)$ & \\
\hline \multicolumn{4}{|c|}{ The average duration of access per week } \\
\hline$\leq 6$ hours & $32(82.1)$ & $7(17.9)$ & \multirow{3}{*}{$0.001^{*}$} \\
\hline 12 hours & $17(73.9)$ & $6(26.1)$ & \\
\hline 24 hours & $29(46)$ & $34(54)$ & \\
\hline \multicolumn{4}{|c|}{ The average duration of access per day } \\
\hline$<30 \mathrm{~min}$ & $48(81.4)$ & $11(18.6)$ & \multirow{4}{*}{$0.001^{*}$} \\
\hline 1-2 hour & $15(55.6)$ & $12(44.4)$ & \\
\hline $2-3$ hour & $8(50)$ & $8(50)$ & \\
\hline$\geq 4$ hours & $7(30.4)$ & $16(69.6)$ & \\
\hline \multicolumn{4}{|c|}{ Time of day when the internet is accessed most } \\
\hline Morning & $31(77.5)$ & $9(22.5)$ & \multirow{5}{*}{$0.003^{*}$} \\
\hline Afternoon & $14(40)$ & $21(60)$ & \\
\hline Evening & $14(77.8)$ & $4(22.2)$ & \\
\hline Night & $10(76.9)$ & $3(23.1)$ & \\
\hline Combination of the above & $9(47.4)$ & $10(52.6)$ & \\
\hline \multicolumn{4}{|l|}{ Activities preferred online } \\
\hline Gaming & $10(90.9)$ & $1(9.1)$ & \multirow{7}{*}{$0.002^{*}$} \\
\hline Instant messaging & 0 & $1(100)$ & \\
\hline Social networking & $10(90.9)$ & $1(9.1)$ & \\
\hline Watching Netflix & $11(78.6)$ & $3(21.4)$ & \\
\hline Seeking information about education & $1(100)$ & 0 & \\
\hline Email & $9(90)$ & $1(10)$ & \\
\hline Combination of the above & $37(48.1)$ & $40(51.9)$ & \\
\hline
\end{tabular}

On associating the Problematic Internet Use and Non-Problematic Internet Use score with selected demographic variable using Chi-square and Fisher's test a significant association was seen for family income ( $<<0.042)$, purpose of internet activities $(\mathrm{p}<0.022)$, applications used $(\mathrm{p}<0.001)$, average duration of access per day and per week $(\mathrm{p}<0.001)$, time of the day when internet is accessed most $(p<0.003)$ and activities preferred online $(p<0.002)($ Table $6 \& 7)$.

\section{Discussion}

Young people, especially adolescents, use the internet much more than any other age group for various purpose such as entertainment, communication with friends, strangers. They are more prone to Problematic Internet Use. This present study was carried by the researcher to explore the impact of Problematic Internet Use among high school students' Academic Performance Additionally; the researchers also intended to shed light on the Academic Stress resulting from Problematic Internet and poor academic performance on adolescents. 
The study assessed the degree of PIU, Academic Performance and Academic Stress among adolescents aged 13-16 yrs. And the study findings have revealed $62.20 \%$ as Normal internet users, 28\% mild PIU users, $8.8 \%$ moderate PIU and $0.80 \%$ were severe PIU users. The pattern of findings was in line with previous reports where it was showed that severe and moderate Internet addictions were reported among $1.9 \%$ and $49.5 \%$ of the students, respectively, whereas the remaining $48.6 \%$ of the adolescents were normal internet users. The mild to the moderate prevalence of Internet addiction revealed in the present study was also justified by Young, 2004, who said that university adolescents have much unstructured time and they use it for leisure activities through internet; instead of utilizing it for academic purpose. Thus, they face stress and have poor performance in exams. In another study conducted by Ismail among adolescents in Zagazig, Egypt, 2007, revealed that the overall prevalence of Internet addiction was 54.6\%, 5.3\% in another study conducted in Riyadh city in Saudi Arabia ${ }^{16}$. Also, a study conducted by Alshehri and his colleagues found that the prevalence of moderate and severe Internet addictions were $45.3 \%$ and $4 \%$, respectively, among Taif University students in Saudi Arabia17,18,19. Severe Internet addiction was found among 13\% of Menoufia University students in Egypt, 2015. In another in South Asia, the prevalence of severe PIU/Internet addiction ranged from $0 \%$ to $47.4 \% 20$. In another study by Abdel-Salam et al,(2019) it was observed, most of the selected sample of 61 (50.8\%) adolescents had moderate levels of internet addiction, followed by $30.8 \%$ of them had high levels of internet addiction and remaining $18.4 \%$ of them had low levels of addiction. It was also concluded based on the study findings of earlier studies that the most noticeable and troubling negative effect of the internet on the adolescent is Problematic Internet Use ${ }^{18}$. Furthermore, it was also seen that compared with other segments of society, adolescents appear to be more vulnerable to Problematic Internet Use due to psychological and developmental variables of adolescents as it relates to easy access to the internet as well as expectations, they have to pertain to internet use.

In the present study, the adolescents with Problematic Internet Use had Academic Stress ranging from mild to severe; mild $-32.80 \%$, moderate- $64.80 \%$, severe- $1.60 \%$ and no academic stress $(0 \%)$ and Academic Performance ranging from Average (60\%), Good (36.80\%) and Excellent 3.20\%. In the case of academic stress, overall, of 125 selected students, majority 63 (52.5\%) of them had moderate Academic Stress and, 51(42.5\%) of them experienced high academic stress. Further, similar findings were reported in study findings by Lancy D’Souza, Manish S and Shravan Raj M.S, 2018 where the majority had moderate to high academic stress, and none of them had low levels of academic stress.

In the present study, a positive relationship was seen for Problematic Internet Use with Academic Stress (r-0.30, $\mathrm{p}<0.01$ ). The findings were supported by studies of previous findings that internet addiction scores were significantly and positively related to most of the factors of academic stress. ${ }^{21}$

The researchers hypothesized the impact of internet addiction on the Academic Performance of adolescent high school students. The current study extended findings of preceding studies that found negative associations between Academic Performance and Problematic internet use ( $\mathrm{r}=-0.174)$. These findings of the study are strongly supported by the study by Griffith (2000). ${ }^{22}$ This negative correlation between internet addiction and academic achievement can be simply explained by the fact that adolescents addicted to the internet tend to spend much time on the computer and as a result of which they have less time to study by Mishra et al, Akhter, and Frangos 23,24,25. However, the findings of the study are contrary to the study reports findings of a number of other studies in the literature. ${ }^{23-30}$

\section{Conclusion}

Findings from the present study revealed that effect of PIU on academic stress was significant and it further lead to poor academic performance. Based on the findings it can be concluded, if the internet use is done by the students in normal limits, it may boost the academic performance of the students; thus enhance their mental health.

\section{Implications of the study}

Several implications are suggested based on the findings of the present study.

- Early prevention should be considered for adolescents with PIU having academic stress and low academic performance by means of: group counselling, conducting Awareness Programme, distributing flyers and organizing Seminars.

- Awareness regarding the effects of excessive internet use among adolescents should be carried

- Parents and Schools also should be made aware of excessive internet use, its impact on the student's academic performance and further distress it causes. 


\section{Limitations of the study}

- The study was conducted in a small suburb school of Kochi. Therefore, the generalization of the findings to the total population of the higher secondary school is limited.

- Further, the study investigated only the impact of Problematic Internet Use on Academic Stress and academic performance.

- More variables that could effect on Problematic Internet Use can be looked into.

\section{Compliance with ethical standards}

\section{Acknowledgments}

We wish to extend our sincere gratitude to the administrative staff, Principal of the Higher Secondary School, Muvatpuzha for granting me permission to conduct this study and for their cooperation. We also would like to express my appreciations to participants for their participation and consent.

\section{Funding}

The current study wasn't funded by any national or international organization.

\section{Highlights / Key Findings:}

- One-fourth of adolescents had Problematic Internet Use

- PIU was associated with excess Academic Stress and low academic performance

\section{Disclosure of conflict of interest}

The authors declare they have no competing interests.

\section{Statement of informed consent}

Informed consent was obtained from parents after explaining the study in brief and also from the subject to ensure the participation of subject. It was also ensured to the subjects that participation in the study was voluntary.

\section{References}

[1] Zhao X. A comparative study on life events of Internet-addicted adolescents. Chin. J. Sch. Health. 2006; 27: 10461047.

[2] Zhou L. Relationships between Internet addiction, coping style and life events among teenagers. Chin. J. Public Health. 2009; 25: 1372-1373.

[3] Wu W. Effect of stress on cognitive biases toward addiction of internet among adolescents. Chin. J. Sch. Health. 2016; 37: 54-56.

[4] Odaci H, Çikrıkci O. Differences in Problematic Internet Use based on depression, anxiety, and stress levels. Addicta. 2017; 4: 41-61.

[5] Jafari N, Fatehizade M. The relationship between Internet addiction and depression, anxiety, stress and social phobia in adolescents of Isfahan University. Scientific Journal of Kurdistan University of Medical Sciences. 2012; 17: 1-9.

[6] John OP, Srivastava S. The Big-Five trait taxonomy: history, measurement, and theoretical perspectives. In L.A. Pervin \& O. John (Eds.), Handbook of personality: Theory and research. 1999; 2: 102-138.

[7] Noftle EE, Robins RW. Personality predictors of academic outcomes: Big five correlates of GPA and SAT scores. Journal of Personality and Social Psychology. 2007; 93(1): 116-130.

[8] Moldasheva G, Mahmood M. Personality, learning strategies, and academic performance. Education Training. 2014; 56(4): 343-359.

[9] Khan MJ, Altaf S, Kausar H. Effect of perceived Academic Stress on students' performance. FWU Journal of Social Sciences. 2013; 7: 146. 
[10] Duchesne SP, Vitaro F, Larose S, Tremblay RE. Trajectories of anxiety during elementary- school years and the prediction of high school noncompletion. Journal of Youth and Adolescence. 2008; 37:1134-1146.

[11] Samaha M, Hawi NS. Relationships among smartphone addiction, stress, academic performance, and satisfaction with life. Computers in Human Behavior. 2016; 57: 321-325.

[12] Safree MA, Yasin M, Dzulkifli MA. Differences in psychological problems between low and high achieving students. The Journal of Behavioral Science. 2009 4(1) 49-58.

[13] Khan, M.J., Altaf, S. and Kausar, H. Effect of Perceived Academic Stress on Students' Performance. FWU Journal of Social Sciences. 2013; 7, 146.

[14] Zsolt Demetrovics, Beatrix Szeredi, And Sándor Rózsa. The three-factor model of Internet addiction: The development of the Problematic Internet Use Questionnaire Behaviour Research Methods 2008, 40 (2), 563 -574.

[15] Mohammad AS, Mohammed A. STUDENT STRESS INVENTORY (SSI) Development, Validity And Reliability of Student Stress Inventory (SSI). https://www.researchgate.net/publication/329555313_STUDENT_STRESS...

[16] Ismail B. Internet addiction and its relationship to personality dimension, psychological disorder for teens. Journal of Educational Faculty, Zagazig University. 2007; 55:33-96.

[17] Alshehri A, Azahrani H, Alotaibi M. Internet addiction among Taif University students and its association with psychiatric co-morbidities. Merit Research Journal of Medicine and Medical Sciences. 2015; 3:536-44

[18] Abdel-Salam, DM, Hajar IA, Haifa K A. Prevalence of Internet addiction and its associated factors among female students at Jouf University, Saudi Arabia Journal of the Egyptian Public Health Association volume 94, Article number: 12 (2019).

[19] Desouky D, Ibrahem R. Internet addiction and psychological morbidity among Menoufia university students, Egypt. American Journal of Public Health Research. 2015; 3:192-8.

[20] Yatan Pal SB, Ananya M, Pawan S, Rachna B. Problematic Internet Use among adolescents in South-East Asia: Current state of evidence. Indian Journal of Public Health. 2018; 62(3): 197-210.

[21] Lancy D’Souza, Manish S, Shravan Raj MS. Relationship between Academic Stress and Internet Addictions among College Students. International Journal of Indian Psychology. Apr-June 2018; 6(2).

[22] Griffiths M. Does Internet and computer" addiction" exist? Some case study evidence. Cyber Psychology and Behaviour. 2000; 3(2): 211-218.

[23] Mishra S, Draus P, Goreva N, Leone G, Caputo D. The impact of internet addiction on university adolescents and its effect on subsequent academic success: A survey-based study. Issues in Information Systems. 2014; 15(1): 344-352.

[24] Frangos CC. Internet Dependence in College Adolescents from Greece. Eur. Psychiatry. 2009; $24(1):$ S419.

[25] Akhter N. Relationship between Internet Addiction and Academic Performance among University Undergraduates. Educational Research and Reviews. 2013; 8(19): 1793-1796.

[26] Kubey, RW. Lavin, MJ. Barrows, JR. Internet use and collegiate academic performance decrements: Early findings. Early findings. Journal of Communication, 51(2), 366-382. https://doi.org/10.1111/j.14602466.2001.tb02885.x

[27] Leung L, Lee PS. Journal of Impact of internet literacy, internet addiction symptoms, and internet activities on academic performance. Social Science Computer Review. 2012.

[28] Panayides P, Walker MJ. Evaluation of the psychometric properties of the Internet Addiction Test (IAT) in a sample of Cypriot high school students: The research measurement perspective. Europe's Journal of Psychology. 2012; 8(3): 327-351.

[29] Rohani F, Tari S. A study of the relationship between the rate of addiction to internet with academic motivation and social development among high school adolescents in Mazandaran Province. Information and Communication Technology in Educational Sciences. 2012; 2(6): 19-34.

[30] Scherer K. College Life On-Line: Healthy and Unhealthy Internet Use. J. College Student Dev. 1997; 38: $655-665$. 34. 